\title{
Route Selection for University Teachers to Assume Social Responsibilities
}

\author{
Xinhe Fu \\ College of Politics, Sichuan Agricultural University \\ Ya'an 625014, Sichuan, China \\ E-mail: ymyyfu@126.com
}

Received: March 24, 2011 Accepted: April 15, 2011 doi:10.5539/ass.v7n8p129

\begin{abstract}
Nowadays, the economic globalization is being continuously enhanced and the competitions of comprehensive national strengths become increasingly fierce. In this case, the social responsibilities that are taken by university teachers become a focus for the whole society. Routes for university teachers to assume their social responsibilities are summarized as follows: keeping pace with the times, imparting knowledge and teaching, striving for career, service and devotion and self-discipline as well as disciplined by others. The exploration of such routes helps university teachers to perform their social responsibilities.
\end{abstract}

Keywords: University teachers, Social responsibilities, Route

As a member of society, the survival and development of an individual cannot be separated from society. Thus, one has to assume social responsibilities and to fulfill corresponding obligations. The stipulation of such responsibilities and obligations is not only the means for one to survive in the society, but also a necessary prerequisite of social development and a basic bond to maintain the relationship among individuals and between individuals and the society.

The so-called social responsibility refers to responsibilities and obligations that one as a member of the society has to bear. It is inherent in each person who lives in a certain social relationship and is the obligatory assumption for each individual to the society. Just as Karl Marx pointed out, "as a certain and real person, you have regulation, mission and task. It doesn't matter at all whether you are aware of that. This task is generated as a result of your demands on and your relationship with the existing world”. (Marx and Engels, 1997)

Universities are the place where higher education is implemented. The university teachers are the main subject for teaching and the decisive factors for universities to undertake their important duties of scientific progress promotion, social development, cultural innovation and cultivation of talents. The university teachers have to consciously assume social responsibilities with the highly responsible attitude for the nation and the society. The social responsibilities of university teachers include not only the mission of professional responsibilities and moral obligations, such as "preaching, teaching, dispelling doubts", imparting knowledge, educating students, transmitting culture and inheriting civilization, but also the important tasks of scientific research and service for the society. Currently, the social responsibilities taken by university teachers receive more and more concerns from the society. Exploration of the routes for university teachers to assume their social responsibilities is conducive for the fulfillment of social responsibilities of university teachers.

\section{To grasp the spirit of the times and to enhance the social responsibilities in keeping pace with the times}

At present, the trend of economic globalization is being continuously enhanced; the exchange in the fields of economy, science and culture, etc. among different countries in the world becomes increasingly frequent and extensive. Accordingly, the competitions of the comprehensive national strength among countries become increasingly fierce. The competition of scientific culture becomes the focus in the competition of comprehensive national strength. The one who has advantages in professional knowledge and scientific innovation can grasp the initiative in development. All countries in the world, especially the developed countries, successively take the promotion of scientific progress and innovation as the national strategy and the development of their own culture as the important task, attempting to enhance competitiveness in science, culture and comprehensive national strength. The contemporary students in universities are the hope of the country, the future of the nation and the 
hard core of the national construction. As the place for knowledge dissemination and scientific innovation and the base for talents cultivation, universities play a more and more important role in leading civilization. The new situation requires university teachers, on one hand, to tread closely on the heels of the step of the times, to get proficiency in the basic theory and specialized knowledge of the subjects they teach, to know about the latest research achievements and the developing trend, to get comprehension with the laws of education and teaching, to use the scientific education methods, to create more discussion opportunities in teaching activities and to make more practice, so that the university students are able to accurately understand the knowledge of the predecessors within the shortest time after a systematic training and strict education and to get close to the leading edge of the modern science and culture. Teachers are required not only to become the disseminators of science and culture, but also become cultivators for various abilities of university students. They conduct comprehensive training for students on the abilities of innovation, analyzing problems, resolving problems, understanding and judging, so that the comprehensive quality of the university students could be practically enhanced. On the other hand, university teachers are required to have deep understanding of the society, especially the characteristics of the transitional period of the society and the new demands of society on the quality of talents, to get comprehension and to know about the characteristics of physical and psychological development of students and to master the ideological and behavioral states of students, then they can educate and teach students with a definite target in the mind, pursue teaching and research achievements in high quality, know about the trend of the times and keep pace with the society.

\section{To set an example and to interpret social responsibilities during teaching and education}

Teaching and education are the work idea and attitude that university teachers ought to set up and are the professional morality that university teachers ought to strengthen. Teaching means that university teachers impart knowledge and skills to students, teach them how to study, build their abilities of innovation and develop intelligence. However, education means that university teachers should not only educate students but also take care of them in the process of education and teaching. The teachers should educate and direct university students with the mainstream thought of the society, help them to set up correct world outlook, philosophy of life, concept of value, moral outlook and legal concept, cultivate a perfect morality and enable university students to become the qualified constructors and successors that the society needed. Teaching enlightens intelligence, whereas education cultivates morality. It is more likely for university teachers to teach their students, but education is usually ignored.

The base of university teachers to "educate people" is that university teachers should gain the appreciation of students with their own noble moral sentiment, perfect style of behavior, profound academic skills and charm personality, set an example, play the demonstrative role as a model and let students spontaneously to recognize, learn and imitate. In order to achieve this, university teachers are required to effectively resist the impacts of utilitarianism, money worship and individualism in the society, resist influences of lack of credibility, exaggerated fickleness, struggle for fame and official standard thinking, pay attention to the accomplishment and exercise of their own moral quality, cultivate perfect learning style, rigorous scholarship, study hard, be creative and realize unification of knowledge and practice. University teachers are also required to have political acuity and discrimination, be able to keep a clear mind in the complex and colorful social situation, firmly preserve the ideal and belief under the impact and influences of various social thoughts, lead the healthy development of students with the mainstream social thought. They are required to go deeply to understand students' ideological state, difficulties and confusions and then guide the students to solve their problems with scientific theory and effective methods. University teachers are asked to not only impart knowledge in the process of teaching, but also pay attention to exploring internal value of the courses, offer correct life outlook, values and moral outlook to students in teaching, direct students to actively think about the future, destiny of the country and the purpose, value of the life. Thus, they can really cultivate qualified social talents, who meet the social demands and are excellent in character and learning. Only in this way, university teachers can well perform the social responsibility of "educating people".

\section{To deal with the relationship between occupation and career and to sublimate social responsibilities in the triving for the career}

For the time being, an important reason for indifferent and weakened social responsibilities among university teachers is that quite a large number of teachers regard the work of education and teaching as an occupation to accomplish, but not as a career to pursue.

Occupation is the work that an individual undertakes in the society as the primary source for his life. As for occupation, university teachers are educator and researcher, their work is nothing more than a means to live, a 
kind of way to survive and a kind of position to eke out their livelihood. If we evaluate the university teachers' work based on this standard, any one is a qualified teacher so long as he observes the rules and regulations of the schools and finishes the assigned teaching and scientific tasks. As a matter of fact, those university teachers who perceive their work in this way are unlikely to devote themselves to their work. As a result, their sense of social responsibilities and their enterprising spirit would be reduced and moreover their educating and teaching work has no improvement, letting alone active, initiative and creative work. In this case, their social responsibilities are certainly unlikely to be realized.

Career refers to the frequent activities that are undertaken by human beings and have definite target, scale and system and have influences upon social development. What career pursues is a kind of state, ideal and target for the life. Pursuit of career may enable university teachers to have strong sense of historical mission and a sacred sense of social responsibilities, to have the enthusiasm and perseverance of striving for the ideal and target, to irradiate the motive for pursuit of career and to realize their social responsibilities to sublimate themselves in the struggle for the career.

To realize the transfer from occupation to career for a university teacher, to love his work and to be devoted to it is the premise. University teachers have to love their work, show respect to the occupation they are involved in, come to full recognition of the importance and urgency of the education and teaching work in universities in the perspectives of the nation, the society and the future and devote them completely to the education, teaching and scientific researches. University teachers have to be deeply aware that occupation is not merely a means to earn the living, but is also an important condition for the continuously socialization of practitioners and is the indispensable stage for individuals to realize themselves and improve themselves. University teachers should take an initiative in improving their knowledge structures, continuously enhancing their own ability and quality, exploring and getting familiar with the laws of education and teaching, realizing the value of life in striving for the career and performing social responsibilities in pursuing success of the career.

\section{To strengthen the consciousness of service and to assume social responsibilities in service and devotion}

In a certain sense, service is the most important topic in teachers' responsibilities. As an important power in the economic and social development of the nation, serving the society is the necessary choice for modern universities. The school motto "Serve the nation and serve the world" in the Princeton University clearly interprets the service idea of the university. As university teachers, they have to set up the consciousness of service and exercise the idea of service, in order to practically assume social responsibilities. This is not only the requirement on teachers by the universities, but is also the key to gain the consciousness of social responsibilities among university teachers. For university teachers, one of the approaches to assume social responsibilities is making service and contributions. That means, to serve the students and the society and to devote them voluntarily. University teachers have to set up the service consciousness of "all for students" and "for all of students" and make themselves actively concern what students are concerned with and worry what students are worried about in the process of teaching and in the daily life. They have to care about the students' life and study, motivate students in their growth and direct students in their thinking. They must guide their education and teaching as well as scientific practice and life practice within the consciousness of service.

In addition, university teachers have to take part in social practice actively, exercise themselves in practice and serve the social and economic development with their knowledge and skills. For university teachers, service for the society is not only the objective requirement of the social development, but also the realistic requirement of their own development; service for the society should not only lay emphasis on "technical service" in the content of service, but also on "ideological service". The service should not only drive economic growth with scientific and technical service, but should also attach great importance to serving the whole society with the ideological idea and lead the development of the social and ideological culture. Furthermore, the service should not only lay emphasis on "comprehensive service" at the service level, but also should attach great importance to "characteristic service", highlight particular advantages and avoid repeated wastes.

\section{To improve the management system and supervision mechanism and to enhance social responsibilities in self disciplines and disciplined by others}

The performance of social responsibilities by university teachers cannot be done without the establishment of a perfect management system and supervision mechanism. This is the so-called "disciplined by others", which means one is directly restricted by others and should accept inspection and supervision from others. Generally speaking, let others to check, let the system to supervise and let the public opinions to monitor. A series of rules and regulations as well as supervision systems that are set up on the basis of heteronomy discipline are used to restrain any improper desires and the teachers' words and deeds, to guarantee the successful operation of their 
education and teaching and ensure the effective of their education and teaching, keep alert university teachers at any time to recognize the objective situation they are faced and remember their own social responsibilities and historical missions in mind. This requires universities to set up and improve a series of regulations and supervision, evaluation mechanisms, such as performance evaluation system, teaching evaluation system, standards of morality, style of teachers and supervision mechanism for any academic misconduct behavior. To set up a multi-evaluation system with combination of qualitative evaluation and quantitative evaluation, coordination of peer evaluation and social evaluation, connection of process evaluation and outcome evaluation and supplement of timely evaluation and delayed evaluation and to set up an overall responsibility of education and rewards mechanism from education to teaching and from management to service.

Enhancing the social responsibilities of university teachers not only depends on restriction from others, but also depends on themselves. The so-called "self discipline" refers to self-constraint, self-check and self-supervision. Generally speaking, one manages oneself and one controls oneself. The self discipline established on the basis of the initiative of university teachers can make them have a clear self-awareness, come to realize the importance of their own profession in the complex and colorful social reality, love their work and devote to the work, make explanation of social responsibilities in their behavior and restrain themselves in strict accordance with the mainstream thought and correct values as well as correct moral requirements in the education, teaching and scientific research ,so they can take an initiative in assuming social responsibilities. Therefore, self discipline is an effective supplement of discipline from others and internalizes the latter into their own behavioral norm. To actively obey the norm enables university teachers to better comprehend and enhance their social responsibilities under the constraints of self discipline and discipline from others. Thus, it is certain that self discipline is an effective approach for university teachers to assume and fulfill their social responsibilities.

\section{References}

Chen, Hua. (2009). Evolvement, Loss and Route Selection for Social Responsibilities of University Teachers from the Reform and Opening up of China. Journal of Linyi Normal University, 02.

Key Teaching Material for Study and Construction Project of the Theory of Marxism: Ideological and Moral Cultivation and Legal Foundation. Beijing: Higher Education Press, $4^{\text {th }}$ Edition, July.

Marx \& Engels. (1997). Karl Marx and Frederick Engels, Vol. 3. Beijing People's Publishing House, p.329.

Wang, Xiuge. (2010). Moral Establishment of University Teachers and Promotion of the Spirit of Universities. Study of Ideological and Political Work, 09.

Yao, Wenfeng. (2008). Ethical Reflection upon Social Responsibilities of Teachers. Journal of Educational Development, the first half of December.

Zhang, Yingqiang. (2009). Social Role and Responsibilities and Mission of University Teachers. Research on Education Tsinghua University, 01. 